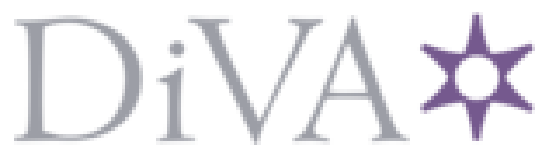

http://www.diva-portal.org

This is the published version of a paper presented at Eurosun 2020.

Citation for the original published paper:

Reddy, S., Saini, P., Zhang, X., Del Amo, A. (2020)

Digital mapping of techno-economic performance of a water-based solarphotovoltaic/ thermal (PVT) system for buildings over large geographical cities In: Digital mapping of techno-economic performance of a water-based solarphotovoltaic/thermal (PVT) system for buildings over large geographical cities https://doi.org/10.18086/eurosun.2020.05.04

N.B. When citing this work, cite the original published paper.

Permanent link to this version:

http://urn.kb.se/resolve?urn=urn:nbn:se:du-37706 


\title{
Digital mapping of techno-economic performance of a water-based solar photovoltaic/thermal (PVT) system for buildings over large geographical cities
}

\author{
Santhan Reddy Penaka ${ }^{1,4}$, Puneet Kumar Saini ${ }^{2}$, Xingxing Zhang ${ }^{1}$, Alejandro del Amo ${ }^{3}$ \\ ${ }^{1}$ Dalarna University, Falun (Sweden) \\ 2 Uppsala University, Uppsala (Sweden) \\ ${ }^{3}$ Abora Solar, Zaragoza (Spain) \\ 4 Penaka Solar AB, Borlänge (Sweden)
}

\begin{abstract}
Solar photovoltaic thermal (PVT) is an emerging technology, capable of producing electrical and thermal energy using a single collector. However, to achieve larger market penetration for this technology, it is imperative to have an understanding of the energetic performance for different climatic conditions and the economic performance under various financial scenarios. This paper thus presents a techno-economic evaluation of a typical water based PVT system for electricity and domestic hot water applications in 85 locations worldwide. The simulations are performed using a validated tool with one-hour time step for output. The thermal performance of the collector is evaluated using energy utilization ratio as efficiency as key performance indicators, which are further visualized by the digital mapping approach. The economic performance is assessed using net present value and payback period under two financial scenarios: (1) total system cost as a capital investment in the first year; (2) only $25 \%$ of total system cost is a capital investment and remaining $75 \%$ investment is considered with financing period with certain interest rate. The results show that such a PVT system has better energy performance for the locations with a low annual ambient temperature and vice versa. Furthermore, it is seen that the system boundaries, such as load profile, hot water storage volume, etc., can have a significant effect on the annual energy production of the system. Economic analysis indicates that the average net present values per unit collector area are $1800 €$ and $2200 €$ respectively among the 85 cities for financial model 1 and financial model 2 . Nevertheless, from the payback period point of view, financial model 1 is recommended for the locations with high interest rate. The study is helpful to set an understanding of general factors influencing the techno-economic performance of PVT systems.
\end{abstract}

Keywords: PVT, Water-based PVT, Techno-economic analysis, Digital mapping

\section{Introduction}

1.1 Background and existing studies

The concept of "electrify everything" considers solar energy as a key renewable technology with an aim of decarbonization of domestic heating demand (Jia, Alva and Fang, 2019). The rapid growth in Photovoltaic (PV) installation capacity from the last few years has further strengthen the importance of PV as the main driver of renewable transformation. (Joshi and Dhoble, 2018). PV remains an interesting subject area for many researchers, global leaders, and manufacturers because of its reliability, sustainability, ease of installation, and economic feasibility (Al-Waeli et al., 2017). However, the concurrence of heat/electricity demand and limited roof area in domestic dwellings does require technologies, which can generate energy efficiently in both thermal and electrical form. Therefore, there is a huge potential for well-designed systems by combining both solar PV and solar thermal technologies. A relatively new commercialized concept of solar photovoltaic/thermal (PVT) technology can achieve such a goal by generating both electrical and thermal energy together using a single panel (Gu et al., 2018). Realizing its importance, the Solar Heating and Cooling Program (SHC) of the International Energy Agency (IEA) has initiated the task 60 for PVT applications and solutions to HVAC systems in buildings ('PVT systems IEA SHC 60 - Annex 180504.pdf', no date). The task is active from January 2018 and has built a huge knowledge base around PVT systems for its use in domestic and industrial applications.

PVT system can be categorized in several ways, however, the most common is based on heat-transfer medium (air based/liquid based) used in the PVT collector (Zhang et al., 2012). The liquid based types are dominating the current PVT market in terms of the number of installations due to high efficiency, and ease of integration in existing hydronic systems (Ramschak, 2020). In a standard liquid based PVT collector, the heat carrier is usually 
water or brine mixture, which is allowed to circulate in a heat exchanger behind the PV cells. The circulation results in a heat transfer through the back sheet of the module, which raises the fluid temperature enough to use for various applications such as hot water, swimming pool heating etc. From a technical perspective, PVT technology is well developed and it can be coupled with various energy systems. For instance, it can go hand-inhand with the emerging awareness of heat pump technology with/without borehole storage ('IEA-SHC-Task60Highlights-2019.pdf', no date). However, the main barriers currently in PVT development and deployment are lack of testing standards, uncertain financial incentives, and business models across different regions in a niche market. Therefore, the business potential of PVT solution is not fully explored, although it can be a very efficient solution for domestic and industrial heating requirements.

However, most of the existing techno-economic studies focused on a single climate, with a straightforward economic-financial analysis. Furthermore, complicated procedures or individual software are used to estimate the performance of PVT collectors, where it lacks a comprehensive simulation of PVT techno-economic performance through a common tool over a large geographic area, aiming for application feasibility and business potentials. Besides, many studies have reported solar energy resource potential on buildings at different spatial scales using digital mapping methods, such as digital numerical maps (Jung, Han and Kim, 2019), digital surface model (Oh and Park, 2018), satellite imageries and geographic information systems [25, 26], multi-scale uncertainty-aware ranking of different urban locations (Peronato et al., 2018), which provide direct evaluations for solar application, leading to robust planning decisions. Nevertheless, no study is found yet for mapping of techno-economic performance of PVT systems.

As a result, this paper aims to fill these research gaps by utilizing a validated simulation tool to perform a comprehensive techno-economic performance simulation for a wide range of cities. The results are further analyzed and visualized using a digital numerical mapping approach to set a comparison among various regions.

\subsection{Aim and objectives}

This study aims at simulation and mapping of the energetic and economic indicators of a typical PVT system over different regions, to establish a digital performance database for various key performance indicators (KPI). The economic feasibility of the PVT collector is obtained and compared under various financial scenario models. The data obtained from simulations are used to establish a simple correlation between variables affecting the PVT system.

The main objectives of this paper are to:

- Assess the thermal and electrical performance of a typical PVT system [6] in 85 locations across the World using a validated simulation tool.

- Evaluate the economic performance using NPV and payback period using two financial scenarios.

- Analysis and visualization of energy and economic performance.

The significance of this paper lies in (1) understanding of typical PVT components behavior at system level, (2) mapping of the collector energetic and economic performance at different climatic conditions across the world. This research results would reflect the concrete developments to this subject area and helps the promotion of the potential markets, e.g. discovering the economic feasibility of the PVT system, and feasible financial solutions to the PVT system in different regions. This paper evaluates the related business benefits of a typical PVT system, which would help to develop a database as repository of PVT performances in different regions and contexts. The research results will be useful for researchers, planners, and policy-makers to further evaluate PVT potentials in a net-zero/positive energy district towards energy surplus and climate neutrality.

\section{System description and research methodology}

This paper focus on a typical PVT collector developed by a Spanish manufacturer named Abora solar. The collector is market available and more than $5700 \mathrm{~m}^{2}$ of the gross collector is installed for a broad range of applications. The collector is a covered PVT type with an additional layer of glass on the top of the collector (in addition to a glass layer for PV cells) to reduce the heat convection losses. The rated power of the collector is $365 \mathrm{~W}$ at Standard Testing Conditions (STC), with a collector area of $1.96 \mathrm{~m}^{2}$ consisting of 72 mono-crystalline cells. The main specifications and characteristics of analysed PVT collector are shown in

Table 1. 
Table 1. Specifications and characteristics of the modelled PVT collector

\begin{tabular}{|c|c|}
\hline Parameter & Description \\
\hline Length $*$ width $*$ thickness & $1970 * 995 * 107 \mathrm{~mm}$ \\
\hline Gross collector area & $1.96 \mathrm{~m}^{2}$ \\
\hline Number of PV cells & 72 \\
\hline Cell type & Mono-crystalline \\
\hline Rated power & $365 \mathrm{Wp}$ \\
\hline Electric efficiency at STC conditions & $17 \%$ \\
\hline Thermal efficiency at STC conditions & $70 \%$ \\
\hline Temperature coefficient of PV & $-0.41 \% /{ }^{\circ} \mathrm{C}$ \\
\hline Thermal efficiency at zero mean temperature & 0.7 \\
\hline Coefficient of thermal losses, $\mathrm{a}_{1}$ & $5.98 \mathrm{~W} / \mathrm{m}^{2} \cdot \mathrm{K}$ \\
\hline Coefficient of thermal losses, $\mathrm{a}_{2}$ & $0.021 \mathrm{~W} / \mathrm{m}^{2} \cdot \mathrm{K}^{2}$ \\
\hline Internal water volume & $1.78 \mathrm{Litres}$ \\
\hline
\end{tabular}

2.1 Research methodology

The simulation is carried using a validated tool developed by the manufacturer of the studied PVT collector. The "Abora hybrid simulation tool" (Contact, no date) was used to map the performance across 85 cities shown in Fig 1. The cities were chosen based on population density and geographical coordinates in different countries to represent a large market potential in these regions. The simulation tool accepts a wide range of design and financial input parameters, e.g. location and weather resources, electrical and thermal demands, local energy tariffs, specific storage volume, PVT panel and installation parameters, interest rate, and financing period, etc. The performance model used in the tool for evaluation of PVT performance is validated in [24], where a heat pump system integrated with 25 PVT modules was monitored, and measurements were also compared with the dynamic simulation model built in TRNSYS for Zaragoza, Spain.

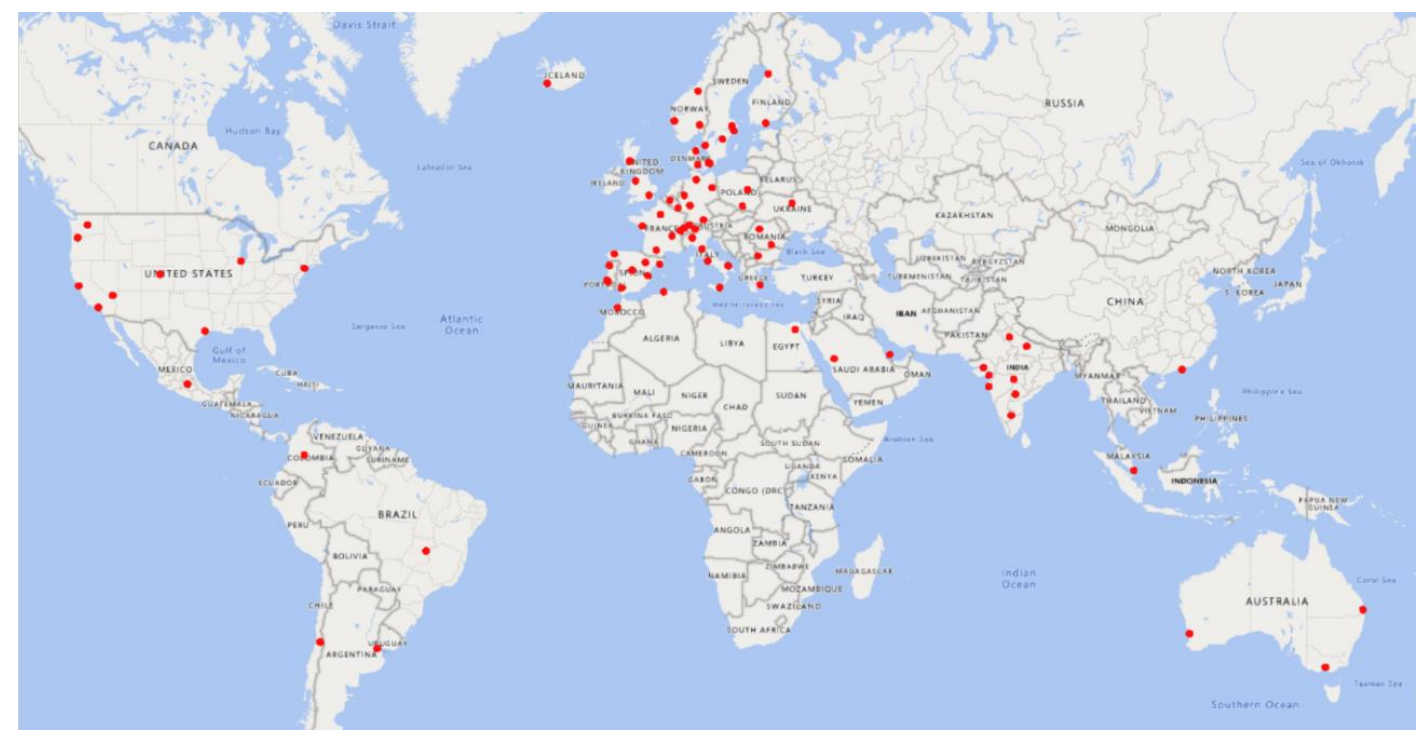

Fig 1. The simulated locations for techno-economic analysis

This paper further applies the digital numerical map approach based on heat maps to visualize the performance of various indicators across simulated locations. The simulation results for all locations are exported to Microsoft Excel for calculations of energy efficiency (Microsoft Excel, Spreadsheet Software, Excel Free Trial, no date). After then, the results are visualized using QGIS tool, which provides a heat map rendering to design a point layer data with a kernel density estimation processing algorithm (Welcome to the QGIS project!, no date). Initially, a 
parametric study of components at the system level is considered according to the operation flow of the simulation tool indicated in the flow chart shown in Fig. 2. Then, the simulations are carried with defined boundary conditions and the results are represented subsequently as monthly electrical and thermal performances, energy savings, economic parameters, such as NPV, payback period.

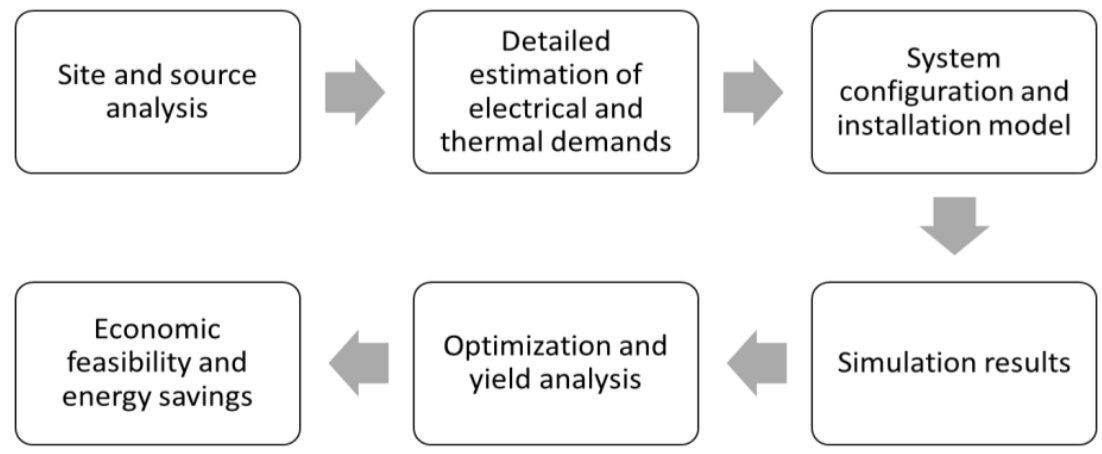

Fig. 2. Operation flow of the simulation tool

This paper also considers the economic performance of the collector in two different financial models, which are described below:

- Model 1: The total system cost is invested in the first year.

- Model 2: Only $25 \%$ of total system cost is a capital investment and the remaining $75 \%$ investment is considered with the financing period with a certain interest rate.

The boundary conditions for the analysis is shown in Table 2.

Table 2. Boundary conditions for the simulation tool

\begin{tabular}{|c|c|}
\hline Parameter & Description \\
\hline Type of application & Single-family house \\
\hline Type of demand & Electricity demand, and Thermal demand for DHW, \\
\hline Auxiliary system & Electrical heater \\
\hline Auxiliary system energy price & This has been selected for the appropriate location \\
\hline No. of people in house & 5 \\
\hline DHW temperature & $60{ }^{\circ} \mathrm{C}$ \\
\hline Collector model & aH72SK \\
\hline No. of collectors & 1 \\
\hline Specific volume capacity & 80 liters $/ \mathrm{m}^{2}$ \\
\hline Inclination & $\begin{array}{l}\text { These were selected optimally based on a parametric } \\
\text { study for maximum energy production. }\end{array}$ \\
\hline Type of mounting structure & Tilted \\
\hline Type of inverter & Single-phase inverter \\
\hline Annual maintenance cost & $\begin{array}{l}\text { Assumed that no maintenance is required for a single } \\
\text { collector to reduce uncertainties. }\end{array}$ \\
\hline Electricity and combustible price increment & $6 \%$ per year is assumed for all the locations \\
\hline System lifetime & 25 years \\
\hline Interest rate & Selected appropriately for each location \\
\hline
\end{tabular}

Initially, the energy performance of the PVT system is simulated in 85 different locations using the simulation tool. In order to discover and compare the collector energy performance in different locations, the thermal demand is maintained the same in all selected locations. Therefore, the simulated system considers a single PVT collector $\left(1.96 \mathrm{~m}^{2}\right)$, for a single-family house application with 5 people, for the same demand, and the same tank volume 
for all locations. These assumptions provide a common system boundary to understand the effect of climatic variables and financing parameters on collector performance. Two types of demands are considered as DHW and electricity use in the building. In the electricity model, no price difference in self-consumed and exported power to the grid is considered. In the thermal system configuration, the auxiliary source for the house is the electricity grid with appropriate energy prices for every location. The generated DHW by the collector is utilized for household purposes using a storage tank connected to the auxiliary system which will deliver demand at the desired temperature of $60{ }^{\circ} \mathrm{C}$. For each location, the installed tilt and azimuth angles are taken optimally based on higher collector production. The specific volume capacity is assumed 80 liters $/ \mathrm{m}^{2}$ for all the locations which is equivalent to total 150 liters of storage tank capacity.

In the proposed simplified energy system, PVT collector is directly connected to the tank without any internal or external heat exchanger. The cold water from the tank enters the PVT module, exchange heat from the absorber, and hot water is fed to the top of the tank. The DHW cold water enters at bottom of the tank, and hot water leaves from top of the tank for DHW supply in building. The DHW distribution system and associated heat losses are not considered in the analysis. The maximum DHW supply temperature is set at $60{ }^{\circ} \mathrm{C}$, and an electric auxiliary heater is provisioned in the tank for periods when the energy from PVT modules is not enough to meet the DHW load. Electric heater starts and stops at the determined dead band to optimize energy consumption, while maintaining the fixed supply DHW temperature. During the periods when tank temperature exceeds the set limit, the energy from PVT modules is fed to a heat sink (air/water heat exchanger), and this spilled energy from the collector is not counted as part of useful energy output.

In the electrical system configuration, the generated DC power will be converted to the AC power using an inverter. Then, it is utilized by household purposes and the remaining will be sent to the electricity grid, whereas the excess electricity demand is taken from the grid connection. As the tilt angle of the PVT collector is a key parameter that will also decide the collector production, a preliminary parametric study is carried for each location to determine the optimal tilt angle for maximum annual collector production.

The total system cost is determined using variables such a module cost, system components cost, annual operation, and maintenance cost. The electricity and auxiliary energy price escalation is assumed $6 \%$ per year for all the locations. The payback time and NPV are estimated by considering a reference system using an electric heater.

The economic performance of the collector in two different financial models is evaluated based:

- Model 1: The total system cost is invested in the first year,

- Model 2: The total system cost is paid for 7 years with a certain variable interest rate with every location.

\section{Results and Discussion}

\subsection{Energy performance evaluation of PVT panel}

\subsubsection{Collector thermal production}

The simulated results are visualised using geo-spatial maps, as they provide a clear indication for the understanding of regional trends for thermal and electrical output despite large data sets. Fig. 3 shows the variation in the thermal output of the collector. 


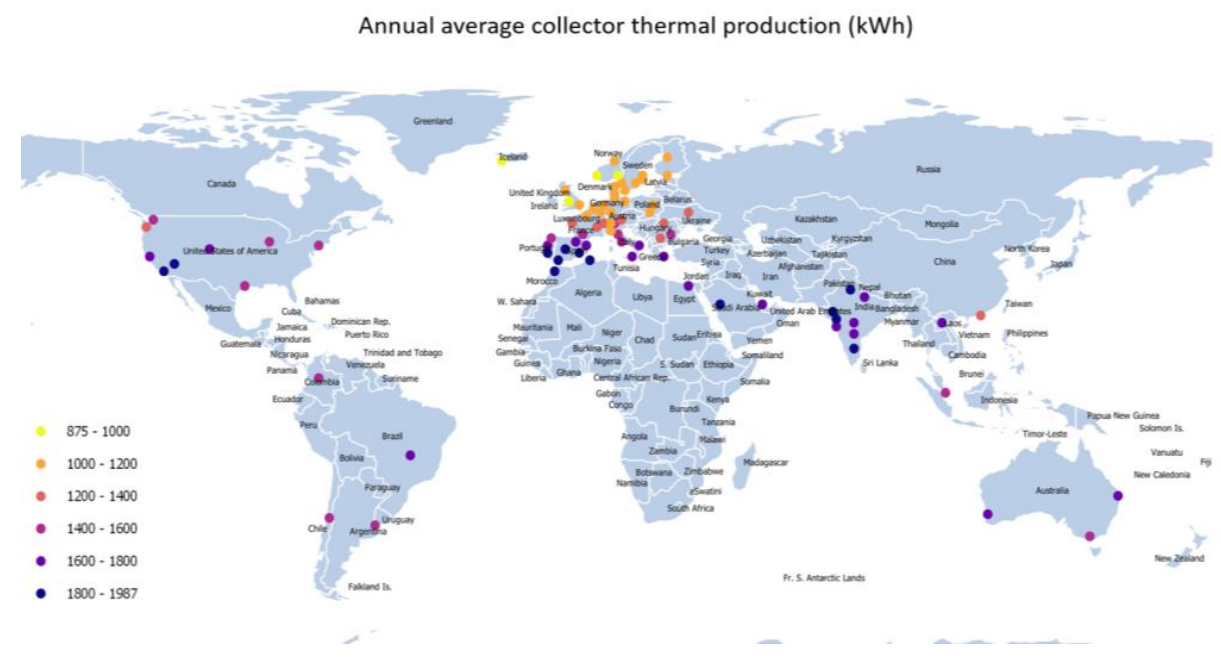

Fig. 3. Annual average collector thermal performance

The general trend shows that thermal output is higher in countries with higher irradiation such as Saudi Arabia, Algeria, Morocco, Brazil, Mexico, India, etc., with annual thermal production above $1800 \mathrm{kWh}$ (area-specific output $918 \mathrm{kWh} / \mathrm{m}^{2}$ ) due to high GHI and ambient temperatures. The lower band of average collector production can be seen in Reykjavik, Iceland and for some locations in Norway with a specific output of $475 \mathrm{kWh} / \mathrm{m}^{2}$ and $500 \mathrm{kWh} / \mathrm{m}^{2}$ respectively. Similar thermal output is obtained for locations in counties such as Sweden, Finland, United Kingdom, Denmark, etc., with less than $510 \mathrm{kWh} / \mathrm{m}^{2}$ annual production. The collector shows better performance in countries, such as Spain, Portugal, and Australia with collector production of above $1600 \mathrm{kWh}$ $\left(816 \mathrm{kWh} / \mathrm{m}^{2}\right)$.

\subsubsection{Collector electrical production}

Fig. 4 represents the electrical performance of the collector, which shows similar trends as thermal output. For locations in countries with high GHI such as Saudi Arabia, Algeria, Morocco, Brazil, India, etc have generation above $500 \mathrm{kWh}$, and peak value in Saudi Arabia with $540 \mathrm{kWh}$. The electrical production is much less in Iceland with $266 \mathrm{kWh}$ due to less available GHI, And the collector lower than $300 \mathrm{kWh}$ in locations, such as Sweden, Finland, Denmark, Poland, United Kingdom, etc., The collector performed slightly better in Spain, Portugal, and Australia with more than $400 \mathrm{kWh}$ annually. However, it shows there is no significant difference in thermal and electrical production trends. Furthermore, a correlation of collector electrical production with GHI and ambient temperature is developed based on all monthly points from all chosen locations and a positive correlation is realized as shown in Fig. 5. A large variation in electrical output for similar values of ambient temperature can be observed, which again shows that GHI is the critical parameter governing the electrical output of the collector.

Annual average collector electrical production (kWh)

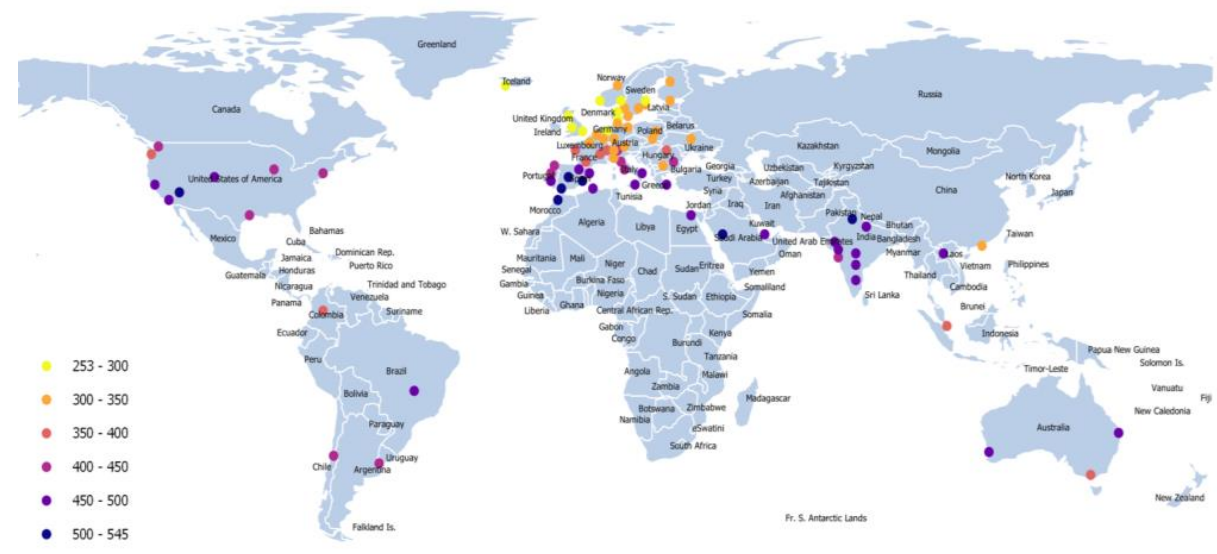

Fig. 4. Annual average collector electrical performance 


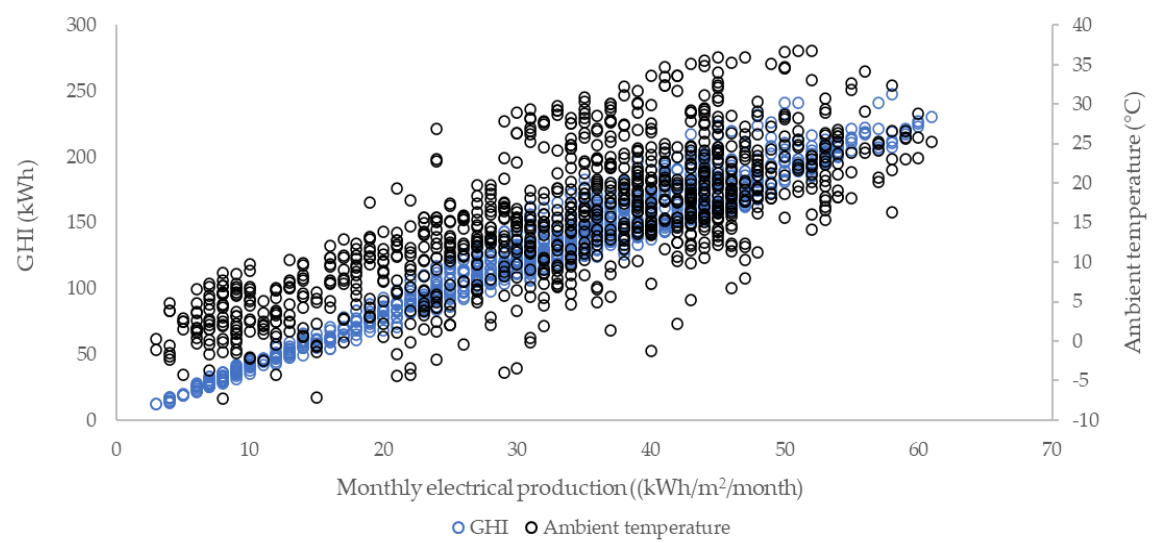

Fig. 5. Correlation of collector electrical production with Global Horizontal Irradiation (GHI) and ambient temperature

\subsubsection{Collector energy utilization ratio}

The energy utilization ratio of the collector for various locations is shown in Fig. 6. The correlation trends between energy utilization ratio and annual average ambient temperature are shown in Fig. 7 with consideration of all selected 85 geographical locations to derive a possible trend between the parameters.

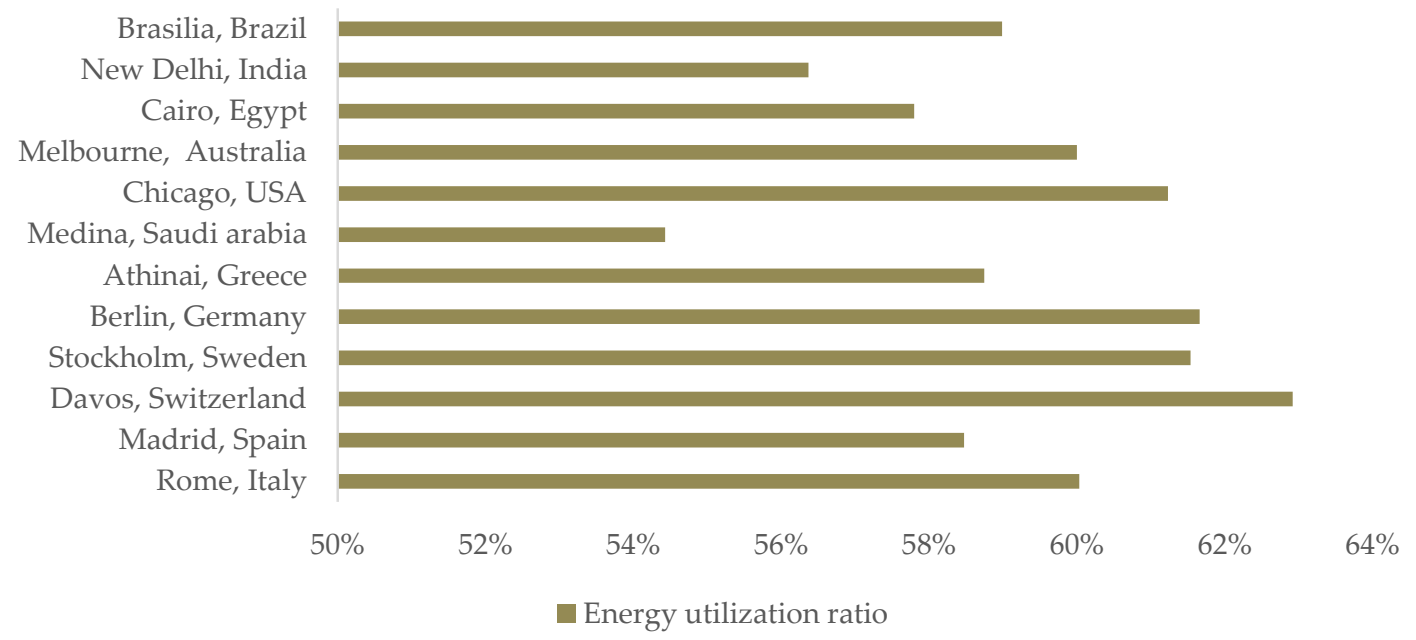

Fig. 6. Collector energy utilization ratio

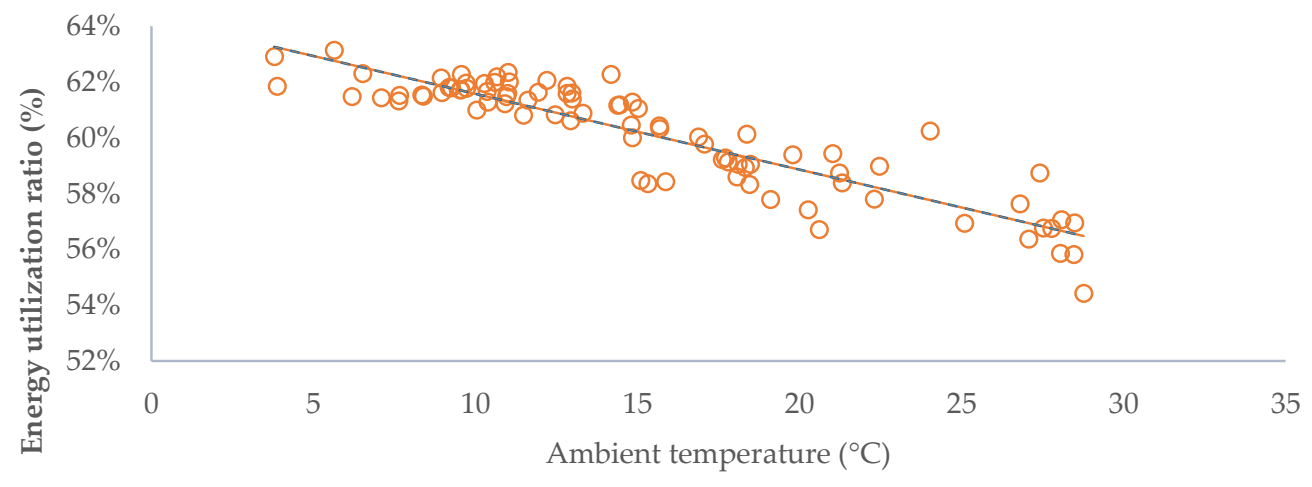

O Energy utilization ratio

Fig. 7. Correlation of Energy utilization ratio with the annual average ambient temperature 
Some locations show interesting results of system boundaries on PVT collector performance. This can be realized by comparing the energy utilization ratio for Medina (high irradiation) and Davos (low irradiation location). The energy utilization for Davos (63\%) is higher compare to Medina $(52.5 \%)$, even though the absolute value of total energy output is higher for Medina (2506 kWh), compared to Davos (1988 kWh). This is because the load demand for Medina is comparably lower, while the other system design parameters remain the same (collector area, tank volume, etc.), which resulted in higher average tank temp, and thus lower collector efficiency for Medina. Results show that the total thermal demand for every location is varying depending on the ambient temperature. It is because of the temperature difference between the annual average ambient temperature of each location and desired water temperature (assumed $60^{\circ} \mathrm{C}$ ), which has to be covered by the collector thermal production

\subsubsection{Collector economic performance in Financing model 1}

This financing model scenario has assumed that the total cost of the system is invested in the first year of the system period. As the total system cost will be invested in the first year, no interest rate is not considered. Fig. 8 is the digital representation of NPV potential per unit collector area with financial model 1 in all 85 geographical cities across the World and Fig. 9 shows the NPV potential per unit collector area in geographical cities in the European continent.

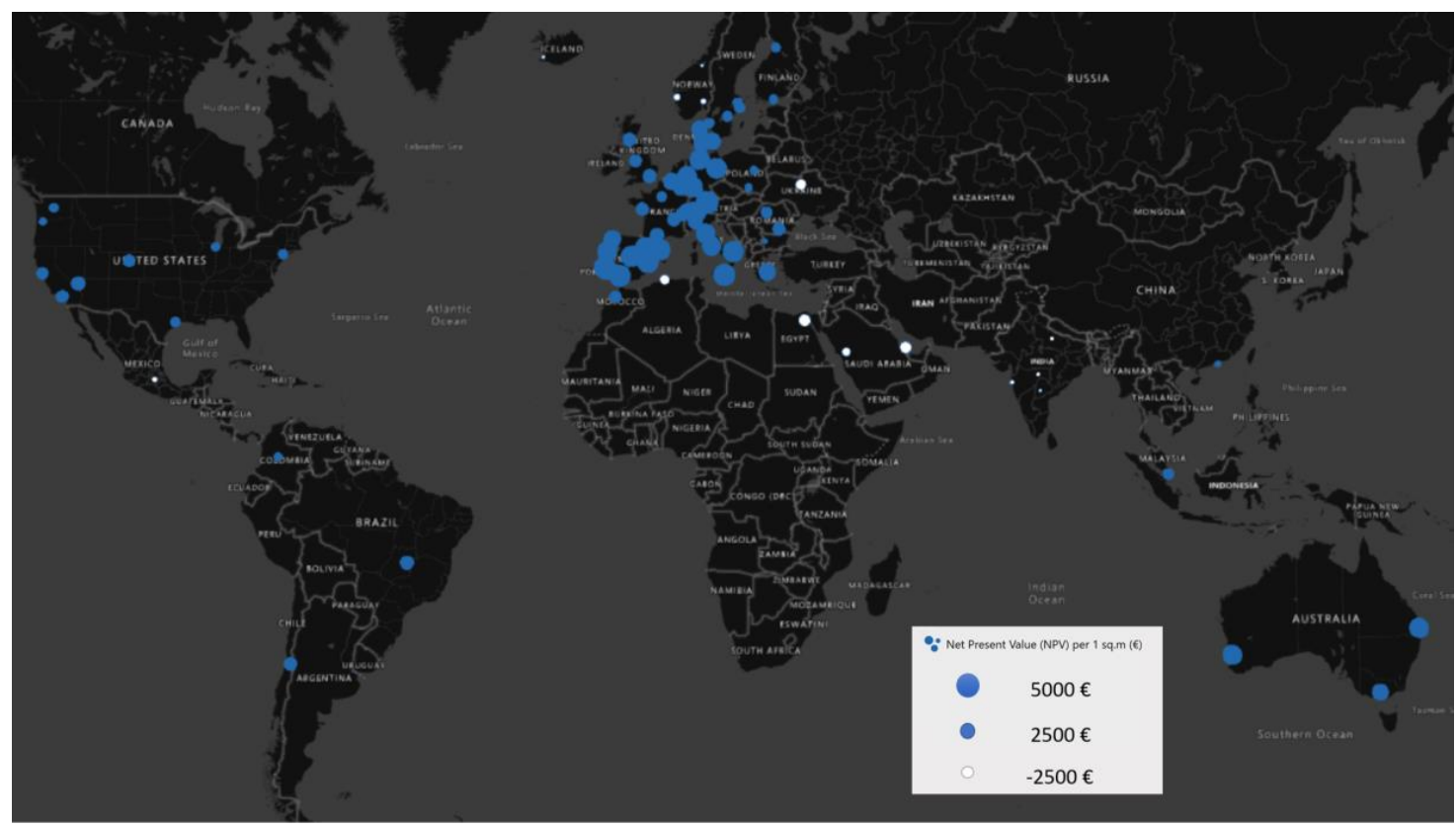

Fig. 8. NPV potential per unit collector area for financing model 1 


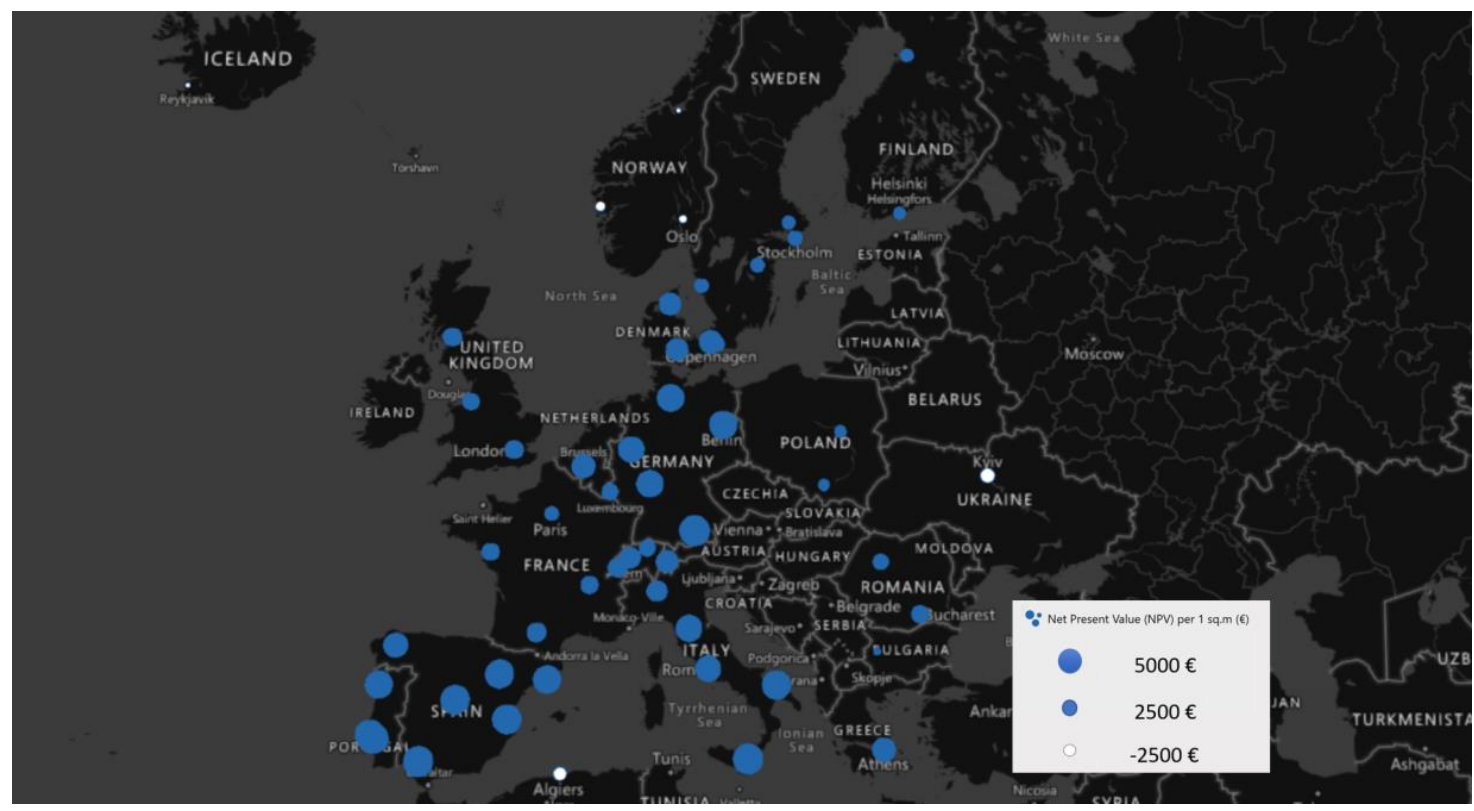

Fig. 9. NPV potential per unit collector area in Europe for financing model 1

The cities with larger dots represent the high NPV potential and cities with smaller dot size represents the least NPV potential. The cities Catania and Munich have the highest potential of $5140 €$ and $5348 €$ respectively, followed by Bari, Lisbon, Setubal, Sevilla, Valencia, Zaragoza, Madrid and Berlin cities has potentially more than $4500 €$ per unit collector area. This is due to their high available GHI and electricity grid price, so the energy savings are high in these locations which reflected in huge NPV potential for this system. Although cities, such as Oslo, Bergen, Reykjavik, etc., with relatively less electricity grid price, resulted in negative NPV due to lower available GHI. The cities with high collector production such as Medina, Algeria, Cairo have shown negative NPV potential due to a very less electricity grid price which eventually showed fewer energy savings.

The NPV potential in all 85 simulated cities has been selected divided and segmented for the appropriate countries to define the NPV range per unit collector area of each country as shown in Fig. 10. A large variation in NPV can be seen in few countries, such as Italy, Portugal, due to variability in GHI for simulated locations. However, a smaller variation is identified in countries such as China, Argentina, Brazil, etc., this is because only one city has been simulated in this paper, which is part of the key uncertainty.

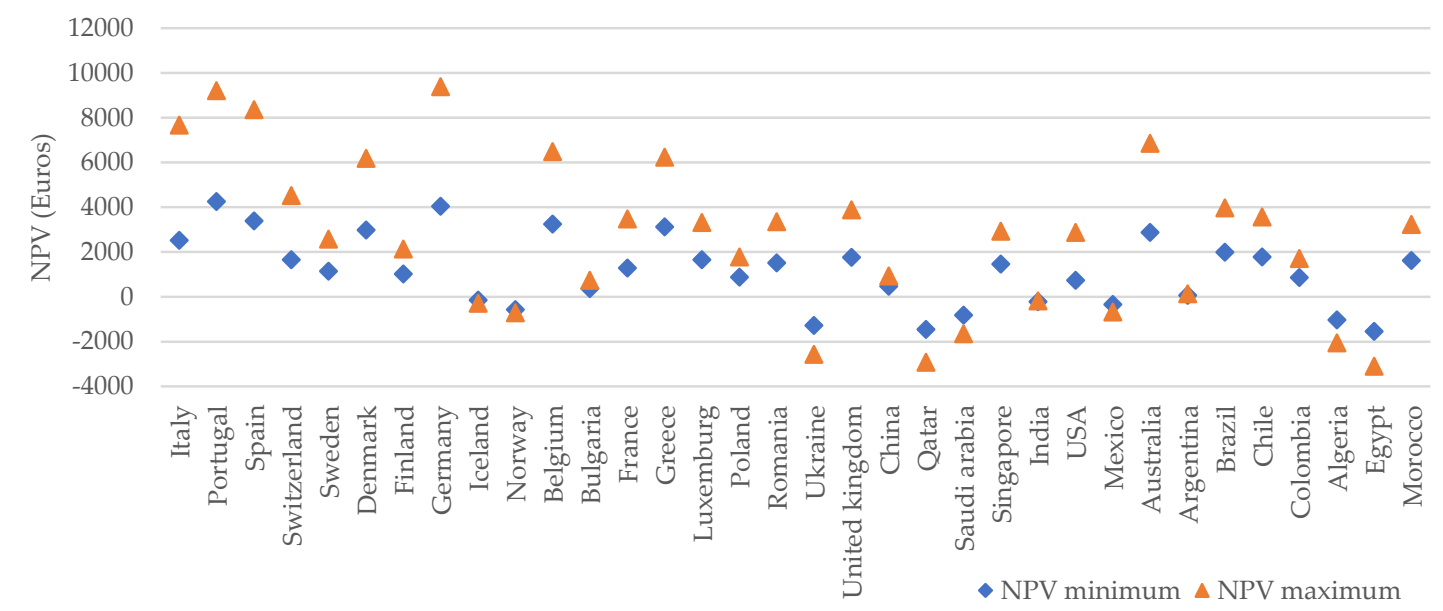

Fig. 10. Country-wise NPV potential per unit collector area for financial model 1

Fig. 11 shows the payback period of this PVT system for a single-family house of 5 people in several countries based on financial model 1 . The results show that the total system cost will be returned in the first 10 years in countries, such as Australia, Belgium, Denmark, Germany, Greece, Italy, Portugal, Spain, Switzerland, etc. This 
is due to high collector production and high electricity grid price. Although countries such as Algeria, Saudi Arabia, Egypt have the highest collector production, the grid price is comparatively lower, which reflects the payback period of more than 20 years.

\section{Payback Period (Years)}

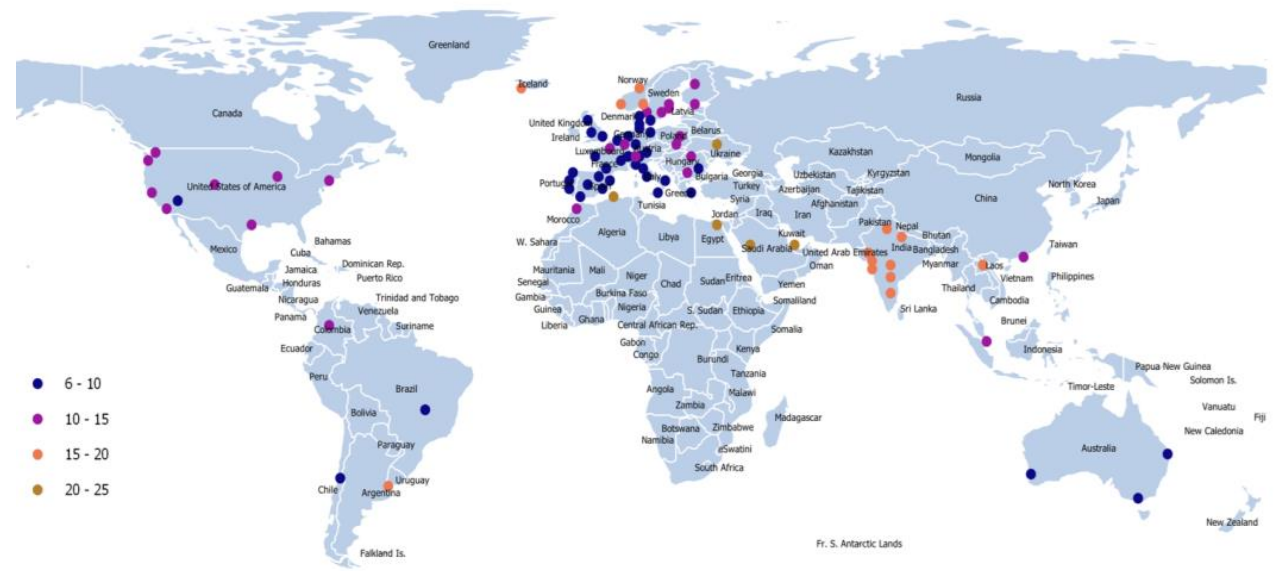

Fig. 11. Country-wise average payback period of the PVT collector system

\subsubsection{Collector economic performance in financing model 2}

This financing model has been analyzed by assuming that $75 \%$ of total system cost is paid within a financing period of 7 years with a certain interest rate and the remaining $25 \%$ of total system cost is invested in the first year without any interest rate. The NPV potential per unit collector area with financing model 2 in 85 geographical cities across the world is shown in Fig. 12 and NPV potential per unit collector area in a specific European continent is shown in Fig. 13.

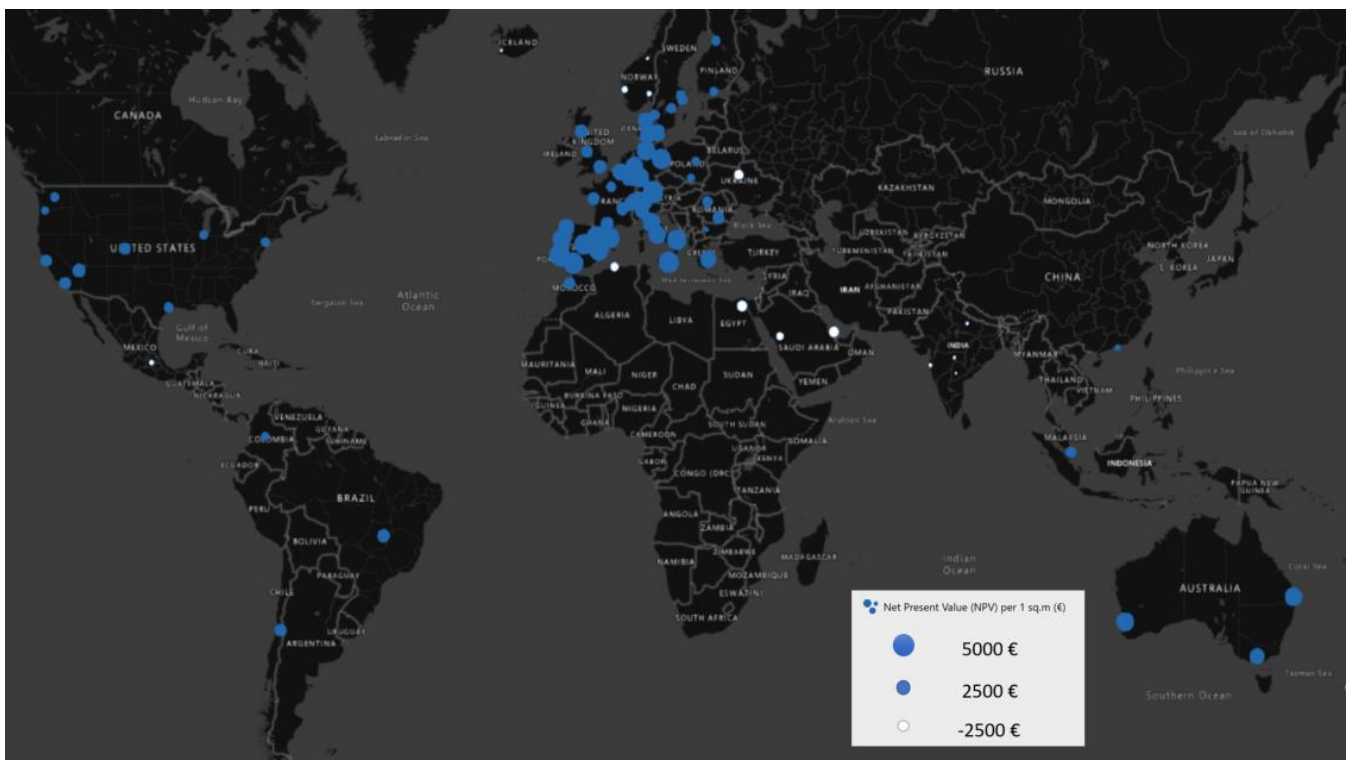

Fig. 12. NPV potential per unit collector area for financing model 2 


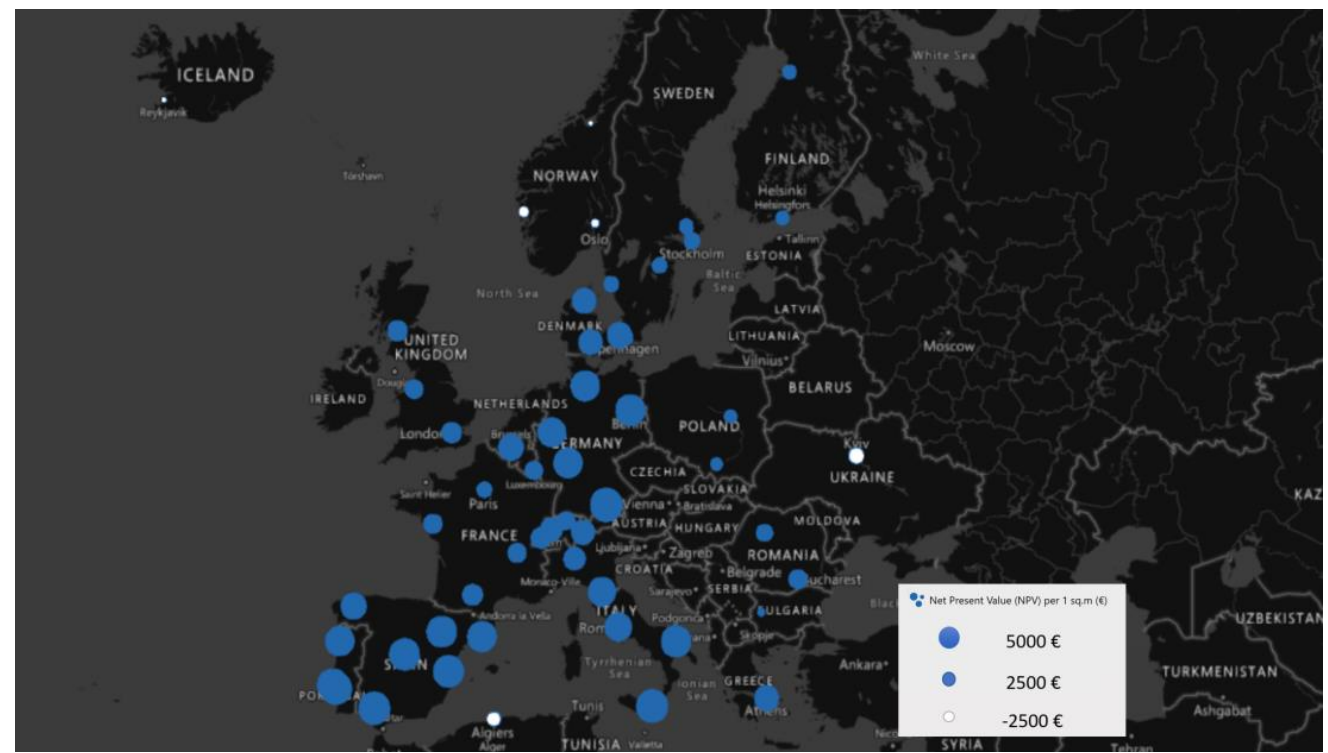

Fig. 13. NPV potential per unit collector area in Europe for financing model 2

The cities with larger dots represent the high NPV potential and cities with smaller dots represent the lower NPV potential. The cities performed high NPV potential in financing model 1, such as Catania and Munich, which has shown improved NPV of $5140 €$ and $5348 €$ respectively because of Zero interest rates in those countries. This is because if the interest rate is zero, the user needs to pay the part of system cost in later years, and the present value of this investment will be lower due to the time value of money. This will reduce the accumulated investment and thus higher NPV. However, if the interest rate is high, the extra amount paid due to high interest in later years, which will overweigh the advantage due to the time value of money and it will decrease the overall NPV. Therefore, Financial model 1 is recommended for countries with high interest rate to maximize the NPV, and minimize the payback. Whereas, financial model 2 is recommended for counties with zero or lower interest rates to maximize the NPV. The effect of NPV change due to financial model 2 compare to model 1 is shown in Fig. 14. As expected, the countries with high interest rate have shown a negative effect on NPV and countries with less and zero interest rates has shown better NPV potential, such as USA, Australia and most of the European countries. However, due to high interest rate of $38 \%$ in Argentina, a huge negative impact is identified with this financing model 2.

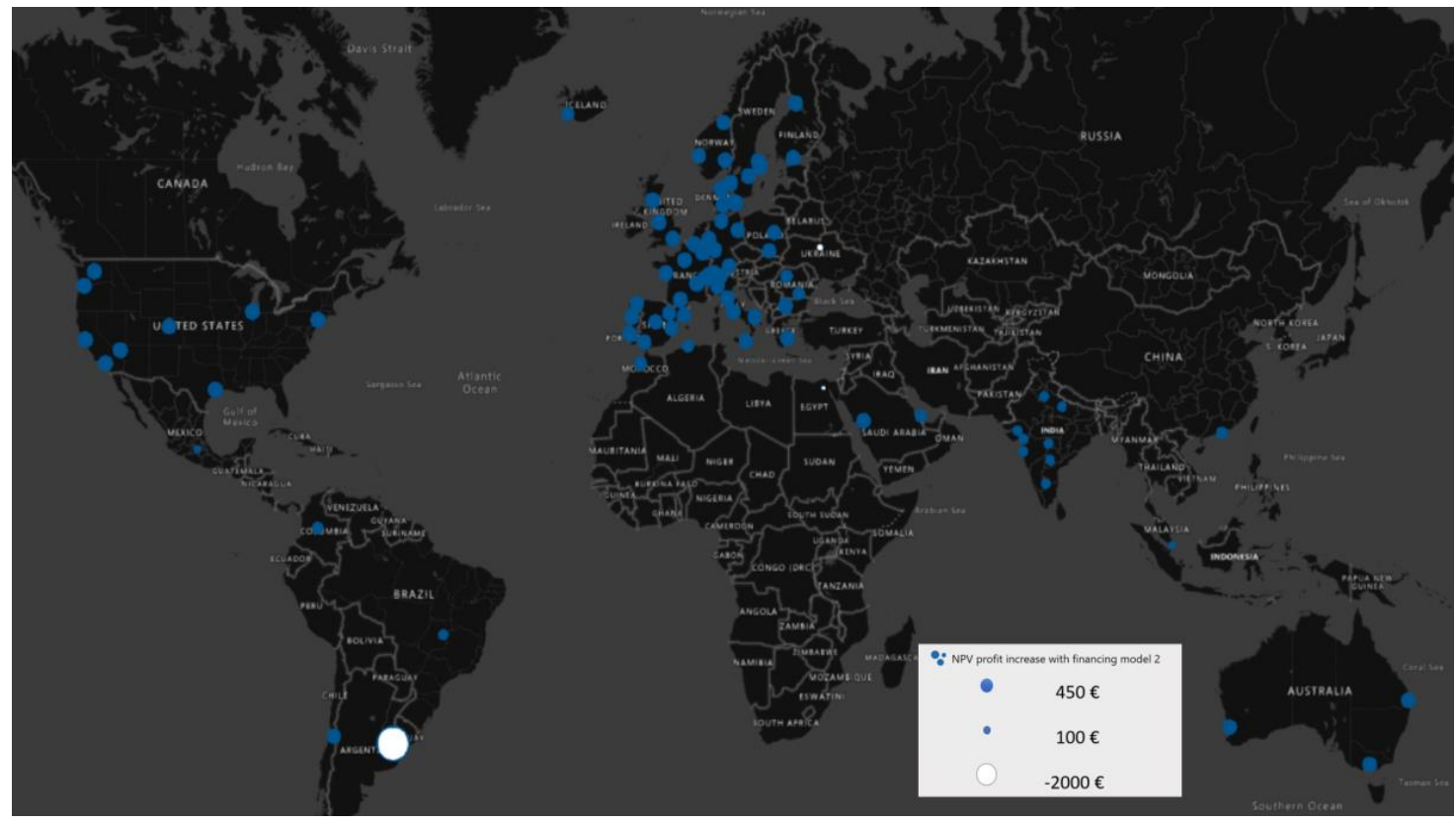

Fig. 14. NPV profit increase with financing model 2 


\section{Conclusions}

The performance of an energy system consists of a PVT collector performance and storage tank is evaluated for 85 locations across a large cities. The optimal tilt angle of PVT collector, load demand, and electricity prices are chosen appropriately for each simulated location. The results show that the major parameter influencing the PVT performance is GHI, and results derived a strong linear correlation between collector output and GHI. The other factor influencing energetic performance is ambient temperature, source, and load water temperatures. The energetic utilization ratio is dependent on total thermal demand and specific volume ratio (v/a ratio), as it can have a major influence on the fluid temperature in the storage tank, and thus collector total production. The electrical production by PVT collector is higher in high ambient temperature locations. The highest and lowest energy utilization ratio of the collector is recorded in Reykjavik, Iceland (63\%), and Medina, Saudi Arabia (54 \%) respectively. Most importantly, the results show that the higher energetic output does not guarantee high economic feasibility. There are several factors such as electricity price, interest rate, and selection of financial model which can highly affect the economic feasibility of PVT collector. The average NPV per unit collector area of 85 geographical cities for financial model 1 and financial model 2 is $1886 €$ and $2221 €$ respectively. The NPV and payback period analysis of the PVT system has shown positive results for the cities, which have high collector production and high electricity grid price reflecting high energy savings. However, the financing model 1 is highly recommended for the locations with high interest rates and financial model 2 is beneficial for the locations with less interest rates. This paper offers potential insight into the promotion of the PVT market in different regions.

Author Contributions: S.R. Penaka works on simulation, analysis, and writing. X. Zhang contributes on supervision, concept development, structuring, and writing. P.K. Saini contributes to simulation. A.d. Amo dedicates to simulation and analysis.

Funding: This research received funding from the Germany-Sweden joint project: 'Product and process development for the preparing and realization of complete buildings of various types of use using energy efficient, partially energy independent lightweight construction solutions, ENSECO’.

Acknowledgments: The authors acknowledge the useful gains from the IEA SHC task 60.

Conflicts of Interest: The authors declare no conflict of interest.

\section{References}

1. Al-Waeli, A. H. A. et al. (2017) 'Photovoltaic/Thermal (PV/T) systems: Status and future prospects', Renewable and Sustainable Energy Reviews, 77, pp. 109-130. doi: 10.1016/j.rser.2017.03.126.

2. Bremer, M. et al. (2016) 'A new multi-scale 3D-GIS-approach for the assessment and dissemination of solar income of digital city models', Computers, Environment and Urban Systems, 57, pp. 144-154. doi: 10.1016/j.compenvurbsys.2016.02.007.

3. Contact (no date) Abora Solar. Available at: https://abora-solar.com/en/contact/ (Accessed: 29 November 2019).

4. Gu, Y. et al. (2018) 'Techno-economic analysis of a solar photovoltaic/thermal (PV/T) concentrator for building application in Sweden using Monte Carlo method', Energy Conversion and Management, 165, pp. 8-24. doi: 10.1016/j.enconman.2018.03.043.

5. 'IEA-SHC-Task60-Highlights-2019.pdf' (no date). Available at: https://task60.ieashc.org/Data/Sites/1/publications/IEA-SHC-Task60-Highlights-2019.pdf (Accessed: 10 June 2020).

6. Jia, Y., Alva, G. and Fang, G. (2019) 'Development and applications of photovoltaic-thermal systems: A review', Renewable and Sustainable Energy Reviews, 102, pp. 249-265. doi: 10.1016/j.rser.2018.12.030.

7. Joshi, S. S. and Dhoble, A. S. (2018) 'Photovoltaic -Thermal systems (PVT): Technology review and future trends’, Renewable and Sustainable Energy Reviews, 92, pp. 848-882. doi: 10.1016/j.rser.2018.04.067. 
8. Jung, J., Han, S. and Kim, B. (2019) 'Digital numerical map-oriented estimation of solar energy potential for site selection of photovoltaic solar panels on national highway slopes', Applied Energy, 242, pp. 57-68. doi: 10.1016/j.apenergy.2019.03.101.

9. Microsoft Excel, Spreadsheet Software, Excel Free Trial (no date). Available at: https://www.microsoft.com/en-ww/microsoft-365/excel (Accessed: 29 July 2020).

10. Mishra, T. et al. (2020) 'Assessment of solar power potential in a hill state of India using remote sensing and Geographic Information System', Remote Sensing Applications: Society and Environment, p. 100370. doi: 10.1016/j.rsase.2020.100370.

11. Oh, M. and Park, H.-D. (2018) 'A new algorithm using a pyramid dataset for calculating shadowing in solar potential mapping', Renewable Energy, 126, pp. 465-474. doi: 10.1016/j.renene.2018.03.068.

12. Peronato, G. et al. (2018) 'A toolkit for multi-scale mapping of the solar energy-generation potential of buildings in urban environments under uncertainty', Solar Energy, 173, pp. 861-874. doi: 10.1016/j.solener.2018.08.017.

13. 'PVT systems IEA SHC 60 - Annex 180504.pdf' (no date). Available at: http://task60.ieashc.org/Data/Sites/1/publications/PVT\%20systems\%20IEA\%20SHC\%2060\%20\%20Annex\%20180504.pdf (Accessed: 25 November 2019).

14. Ramschak, T. (2020) /ieashc-task60-2020-0001. IEA SHC Task 60. doi: 10.18777/ieashc-task60-2020-0001.

15. Welcome to the QGIS project! (no date). Available at: https://qgis.org/en/site/ (Accessed: 29 July 2020).

16. Zhang, X. et al. (2012) 'Review of R\&D progress and practical application of the solar photovoltaic/thermal (PV/T) technologies', Renewable and Sustainable Energy Reviews, 16(1), pp. 599-617. doi: 10.1016/j.rser.2011.08.026. 
S.R. Penaka / EuroSun2020 / ISES Conference Proceedings (2020) 